\title{
Impact of vitamin $D$ deficiency on maternal and birth outcomes in the Saudi population: a cross-sectional study
}

\author{
Ghadeer K. Al-Shaikh ${ }^{1,2}$, Gehan H. Ibrahim ${ }^{2,3^{*}}$, Amel A. Fayed ${ }^{2,4}$ and Hazem Al-Mandeel ${ }^{1}$
}

\begin{abstract}
Background: Low serum vitamin D $[25(\mathrm{OH}) \mathrm{D}]$ has been associated with different health problems worldwide. However, its causal role in several diseases remains unclear. We aimed to correlate vitamin D status with maternal and neonatal outcomes in pregnant females.

Method: One thousand pregnant women were recruited during early labour from the labour ward of King Khaled University Hospital, Riyadh, Saudi Arabia. Detailed medical data of all participants were collected from their records. Delivery events and birth outcomes were also documented. Serum 25(OH)D levels were measured using an enzyme-linked immunosorbent assay. A receiver operating characteristic (ROC) curve was constructed to evaluate the ability of vitamin D levels to predict complicated pregnancies. Regression analysis was used to test the correlation between serum 25(OH)D levels and different variables.

Results: Most of the participants were Saudis (89.9\%) and housewives (85.1\%) and $86.4 \%$ of them had vitamin D deficiency (mean: $30.46 \pm 19.6 \mathrm{nmol} / \mathrm{L}$ ). Gestational diabetes mellitus (GDM) was the commonest complication detected (11.1\%) while the history of miscarriage was elevated (24.5\%). There was no association between GDM and low 25(OH)D. Yet, there was a significant negative correlation between serum 25(OH)D levels and fasting blood glucose among females older than 35 years $(r=-0.2, p=0.03)$. Hypertensive disorders of pregnancy and pre-existing hypertension were less than $1.5 \%$ of frequency. Nevertheless, they were only recorded in women with insufficient and deficient vitamin D. ROC curve revealed that 25(OH)D levels were not able to discriminate between normal and adverse pregnancy outcomes (AUROC curve: $0.51 ; 95 \%$ confidence interval (Cl): 0.44-0.58; $p=0.8$ ).
\end{abstract}

Conclusion: Hypovitaminosis D, a highly prevalent health problem among pregnant females in Riyadh, has no relation to adverse pregnancy outcomes except for a higher prevalence of miscarriage in women with low 25(OH)D.

Keywords: Gestational diabetes, Pregnancy, Vitamin D, Hypovitaminosis D, Adverse pregnancy outcome

\section{Background}

Vitamin D, also known as calciferol, is a prohormone that plays an important role in calcium homeostasis and bone health in addition to its neuromuscular functions [1]. Vitamin $\mathrm{D}$ has two major forms, vitamin $\mathrm{D}_{2}$ and vitamin $D_{3}$. They are further metabolized into 25 hydroxyvitamin $\mathrm{D}(25(\mathrm{OH}) \mathrm{D})$ and 1,25- dihydroxy

\footnotetext{
* Correspondence: gehan_amer@med.suez.edu.eg; dr_ghamer@yahoo.fr ${ }^{2}$ College of Medicine, Princess Nourah Bint Abdulrahman University, Riyadh, Kingdom of Saudi Arabia

${ }^{3}$ Department of Medical Biochemistry, Faculty of Medicine, Suez Canal University, Round Road, Ismailia 41511, Egypt

Full list of author information is available at the end of the article
}

vitamin $\mathrm{D}(1,25(\mathrm{OH}) 2 \mathrm{D})$, the active form of vitamin $\mathrm{D}$, in the liver and the kidney, respectively $[2,3]$. $25(\mathrm{OH}) \mathrm{D}$ is the main circulating vitamin $\mathrm{D}$ metabolite and its serum level serves as a biomarker of the vitamin status [4].

Beyond its effect on bone homeostasis, 25(OH)D has been implicated in varying clinical conditions. In the last two decades, the non-classical function of vitamin D has been suggested; it regulates a large number of human genes ( 200 genes), resulting in a wide range of autocrine effects in different tissues [5]. For example, vitamin $\mathrm{D}$ is involved in regulation of cell proliferation, cell 
differentiation, and apoptosis [4]. In addition, it exerts immune responses through regulation of the innate and adaptive immunity [6]. This explains the correlation of hypovitaminosis $\mathrm{D}$ to the potential risk of a series of conditions like hypertension, diabetes mellitus, cancer, multiple sclerosis, allergy, asthma, autoimmune and infectious diseases as well as depression $[7,8]$.

In Saudi Arabia, hypovitaminosis D can be considered a major public health problem with a significantly high prevalence especially among women, ranging from to $\sim 80$ to $100 \%$ in different studies [9-11]. Vitamin D deficiency can be seen not only in infancy and childhood but also across the other life stages from adolescence, adulthood, until old age [12]. The risk of vitamin D deficiency increases during pregnancy due to the increase in maternal and fetal demands [13]. Moreover, vitamin D is postulated to have a potential effect on several pregnancy outcomes including fetal skeletal outcome, hypertensive disorders, and gestational diabetes mellitus (GDM) [14-16]. To our knowledge, there is no published data on the relation of low vitamin D and pregnancy, or fetal development, in the Saudi population. The current study aimed to assess 25(OH)D levels in pregnant females residing in Riyadh, and to correlate the vitamin status to the possible maternal and neonatal adverse outcomes.

\section{Methods}

This is a cross-sectional study where all consecutive pregnant females admitted in labour ward were invited to join the study. The study was conducted in accordance with the guidelines of the Declaration of Helsinki and was approved by the Institutional Review Board (IRB) of King Saud University. All pertinent study information was explained to all participants and they were informed that rejection or withdrawal from the study will not affect any medical service provided. A summarized study information sheet was shown to all cases before obtaining their verbal agreement. Finally, an informed verbal consent was obtained and witnessed by the attending nurse. A log book was created including the participant's study number and the date of consent. The IRB waived the requirement for taking a written consent as the research had minimal risk of harm to subjects and involved no risky procedures for which written consent is required. The study was adherent to the STROBE criteria as outlined in Additional file 1.

\section{Inclusion and exclusion criteria}

Recruitment of 1000 consecutive women was accomplished in the labour ward in King Khaled University Hospital (KKUH), Riyadh, Saudi Arabia, between the beginning of January till the end of June 2014. Exclusion criteria included known chronic illnesses [except hypertension and diabetes mellitus], metabolic bone disease, intestinal malabsorption, any evidence of liver, kidney, or gastrointestinal diseases), and the use of vitamin D supplements and/or other medications that affect vitamin $\mathrm{D}$ level (e.g. anticonvulsants, antituberculosis drugs).

\section{Data collection}

Data on socio-demographics, medical and reproductive history were collected from all subjects. Medical records were abstracted to ascertain their anthropomorphic characteristics as well as their medical status throughout gestation. Participants' pre-pregnancy body weights were not available in the record; pregnancy body mass index (BMI) was calculated using the admission weight and height measurements. All participants were screened for GDM by estimation of $75-\mathrm{g}$ oral glucose tolerance test (OGTT) between 24 and 28 weeks of gestation. Data of OGTT and adverse pregnancy outcomes (e.g. GDM, gestational hypertension, preeclampsia and intrauterine growth restriction based on two measurements, at least, 2 weeks apart) were retrieved from their files. Diagnosis of preeclampsia was based on the new onset of hypertension (systolic blood pressure $\geq 140 \mathrm{~mm} \mathrm{Hg}$ or diastolic blood pressure $\geq 90 \mathrm{~mm} \mathrm{Hg}$ ) after 20 weeks gestation in addition to proteinuria ( $\geq 300 \mathrm{mg} / 24 \mathrm{~h}$ ). Gestational hypertension was defined as De novo hypertension alone, occurring after 20 weeks gestation in a previously normotensive woman [17]. Delivery events (e.g. preterm delivery, caesarean section) and birth outcomes (e.g. anthropometric birth outcomes, APGAR score and neonatal admission to the ICU) were recorded after labour.

\section{Estimation of serum 25(OH)D level}

Blood samples were collected for vitamin $\mathrm{D}$ estimation, and sera were processed and stored at $-80{ }^{\circ} \mathrm{C}$ until analyzed. Quantification of serum 25(OH)D was performed using a commercial enzyme-linked immunosorbent assay (ELISA) (K2110, Immunodiagnostic [Dutch Company], Holland). The range of detection was $5-300 \mathrm{nmol} / \mathrm{L}$. Patients' vitamin D status was evaluated according to the $25(\mathrm{OH}) \mathrm{D}$ concentrations into deficient [Levels below $50 \mathrm{nmol} / \mathrm{L}(20 \mathrm{ng} / \mathrm{ml})$ ], insufficient [concentrations between 51 and $74 \mathrm{nmol} / \mathrm{L}(21-29 \mathrm{ng} / \mathrm{ml})]$ and normal $[25(\mathrm{OH}) \mathrm{D} \geq 75 \mathrm{nmol} / \mathrm{L}(\geq 30 \mathrm{ng} / \mathrm{ml})][18,19]$.

\section{Statistical analysis}

Sample size calculation was based on previous literature findings, where $\sim 83 \%$ of GDM patients suffered from vitamin D deficiency/insufficiency compared to $71 \%$ in non-GDM subjects [20]. Assuming a significance level of $95 \%(\alpha=0.05)$ and a power of $80 \%(\beta=0.20)$, calculation of the sample size revealed that the minimum number of participants required to reject the null hypothesis was 900. Statistical analysis was performed using the SPSS software v.20.0 for Windows ${ }^{\bullet}$ (SPSS Inc., Chicago, 
IL, USA). Data were presented as mean \pm SD and percentages. Univariate analysis and differences between groups were assessed using the Student's $t$-test, or Chi-square $\left(\chi^{2}\right)$ test when appropriate. Receiver operating characteristic (ROC) curve was constructed and the area under the curve (AUC) was calculated to evaluate the specificity and sensitivity of vitamin D levels to predict complicated pregnancies from normal ones. Pearson correlation coefficient was used to test the correlation between quantitative variables. Linear regression statistics were used to determine the relationship between fasting OGTT and serum 25(OH)D levels with adjustment for age, BMI and parity. In addition, logistic regression analysis was adopted to assess the correlation between the history of miscarriage and the vitamin $\mathrm{D}$ levels adjusted for age and BMI. The values of $25(\mathrm{OH}) \mathrm{D}$ were log-transformed to achieve normality. All statistical tests were two-tailed, and a $p$-value $<0.05$ was considered statistically significant.

\section{Results}

The age of women included in the study ranged from 17 to 47 years and $\sim$ half of them were between 25 and 35 years. Most of the participants were Saudis (89.9 \%) and housewives $(85.1 \%)$. Table 1 shows the sociodemographic data, reproductive information and outcomes of the current pregnancy in the studied population. The major form of pregnancy-associated complications was GDM (11.1\%), followed by intrauterine growth restriction and gestational hypertension (1.5 and $1.4 \%$, respectively) and the least one was preeclampsia (0.9\%). Out of the 19 patients (1.9\%) who had pre-gestational diabetes 14 had type- 1 diabetes mellitus (1.4\%) and five had type-2 (0.5\%). Surprisingly, history of miscarriage among pregnant females was highly elevated (24.5\%). According to the pregnancy BMI, $56.7 \%$ of the women were higher than $30 \mathrm{~kg} / \mathrm{m}^{2}$, while $31 \%$ ranged between 25 and $30 \mathrm{~kg} / \mathrm{m}^{2}$ and $12.3 \%$ was below $25 \mathrm{~kg} / \mathrm{m}^{2}$.

Serum 25(OH)D levels ranged from 7.1 to $150 \mathrm{nmol} / \mathrm{L}$. Division of the participants according to their vitamin D status revealed that the majority of women had vitamin D deficiency (86.4 \%; mean: $24.2 \pm 10.6 \mathrm{nmol} / \mathrm{L}$; range: 7.1-49.9). Table 2 shows a comparison between study participants' data, pregnancy and birth outcomes in relation to their vitamin $\mathrm{D}$ status. Women with deficiency were mostly in the middle age group [25-35 years] and they were housewives $(p<0.01$ and $=0.02$, respectively). There was no difference in the GDM frequencies in vitamin D status subgroups. Moreover, there was a significant increase in the percentage of women with positive history of miscarriage in the insufficient status compared to the deficient and normal ones $(p=0.02)$ (Table 2). On the other hand, gestational hypertension, pre-existing hypertension, preeclampsia and pre-existing diabetes mellitus were only recorded in women with deficient and insufficient vitamin D. However, these frequencies did not reach significant levels (Table 2). Furthermore, there was no difference between women with low vitamin D and those with normal vitamin status regarding birth outcomes $(p>0.05)$.

Seventy-four percent of women had a normal pregnancy, delivery and neonatal outcomes. This sub-group of participants had a mean vitamin D level of $29.6 \pm$ $18.9 \mathrm{nmol} / \mathrm{L}$ (range: $7.5-101$ ). A ROC curve was plotted to investigate the potential ability of serum $25(\mathrm{OH}) \mathrm{D}$ to identify normal pregnancy outcomes (Fig. 1). Vitamin D levels were not able to discriminate between normal pregnancies and birth outcomes and any possible complication (AUROC curve: 0.51; $95 \%$ confidence interval (CI): $0.44-0.58 ; p=0.8$ ). A noticed significant age discrepancy was confirmed between vitamin D subgroups. As there might be a co-linearity between age and parity, a stratified analysis of the correlation between 25(OH)D and parity among different age groups was conducted. A weak negative correlation between vitamin $\mathrm{D}$ levels and parity was apparent, especially in older age groups ( $>35$ years) $(r=-0.07, p=0.3)$ (Fig. 2a). On the other hand, a significant negative correlation was evident between the levels of $25(\mathrm{OH}) \mathrm{D}$ and those of fasting OGTT among the oldest age group ( $>35$ years) $(r=-0.2$, $p=0.03$ ) (Fig. 2b). Adjustment for age, BMI and parity via linear regression model revealed a weak negative relationship between serum 25(OH)D and fasting OGGT levels; however, this did not reach statistical significance ( $\beta=-0.07$, adjusted $\left.r^{2}=0.04, p=0.16\right)$. Moreover, logistic regression analysis showed that women with higher levels of vitamin D were less likely to report the history of miscarriage (odds ratio $0.7,95 \%$ confidence interval: $0.35-1.45, p=0.3$ ); yet, this correlation was not statistically significant.

\section{Discussion}

The presence of vitamin D receptors (VDR) in almost every tissue drew the attention to the identification of the extra-skeletal functions of vitamin D [21]. So far, thousands of research have been published to explore the implication of vitamin D in human illness. It has also been correlated to maternal and fetal health during pregnancy [22]. Despite abundant sunlight, hypovitaminosis $\mathrm{D}$ is highly prevalent among the Saudi population. It is more frequent in the young and middle-aged group of apparently healthy Saudi adults [23] and in females more than males [10]. A limited number of publications in Saudi Arabia studied vitamin D deficiency in relation to diseases beyond bone health, e.g. diabetes mellitus [23, 24] and obesity [25]. Al-Mogbel [9] investigated vitamin D levels in Saudi females in the childbearing period and reported that all participants had hypovitaminosis D 
Table 1 Socio-demographic and clinical data of the study population

\begin{tabular}{|c|c|}
\hline Age (years; mean \pm SD [range]) & $29.03 \pm 5.7[17-47]$ \\
\hline \multicolumn{2}{|l|}{ Age distribution $^{\text {a }}$} \\
\hline Less than 25 years & $321(32.2)$ \\
\hline $25-35$ years & $513(51.4)$ \\
\hline More than 35 & $164(16.4)$ \\
\hline \multicolumn{2}{|l|}{ Nationality } \\
\hline Saudi & $899(89.9)$ \\
\hline Non Saudi & $101(10.1)$ \\
\hline \multicolumn{2}{|l|}{ Education $^{a}$} \\
\hline High school & $668(70.4)$ \\
\hline University or higher & $281(29.6)$ \\
\hline \multicolumn{2}{|l|}{ Working status ${ }^{a}$} \\
\hline Housewife & $851(85.3)$ \\
\hline Employee & $147(14.7)$ \\
\hline \multicolumn{2}{|l|}{ Reproductive history } \\
\hline \multicolumn{2}{|l|}{ Parity } \\
\hline Primiparous & $12(31.6)$ \\
\hline Multiparous & $26(68.4)$ \\
\hline Positive history of multiple pregnancies & $56(5.6)$ \\
\hline Positive history of miscarriage & $245(24.5)$ \\
\hline \multicolumn{2}{|l|}{ Status of current pregnancy } \\
\hline Smoking during pregnancy ${ }^{a}$ & $20(0.2)$ \\
\hline $\begin{array}{l}\text { Gestational age till delivery (Weeks; mean } \pm \text { SD } \\
\text { [range]) }\end{array}$ & $38.7 \pm 1.9[23-42]$ \\
\hline Pregnancy BMI $\left(\mathrm{Kg} / \mathrm{m}^{2} ;\right.$ mean $\pm \mathrm{SD}$ [range] $)$ & $30.9 \pm 6.7[14.5-55.8]$ \\
\hline Gestational diabetes & $111(11.1)$ \\
\hline Pre-Gestational diabetes & $19(1.9)$ \\
\hline Pre-existing hypertension & $4(0.4)$ \\
\hline Gestational hypertension & $14(1.4)$ \\
\hline Preeclampsia & $9(0.9)$ \\
\hline Intrauterine growth restriction & $15(1.5)$ \\
\hline \multicolumn{2}{|l|}{ Delivery and neonatal outcomes } \\
\hline Preterm labour & $80(8.0)$ \\
\hline Induction of labour & $128(12.8)$ \\
\hline \multicolumn{2}{|l|}{ Mode of delivery } \\
\hline Spontaneous & $768(76.8)$ \\
\hline Instrumental delivery & $61(6.1)$ \\
\hline Caesarian Section & $171(17.1)$ \\
\hline Baby's weight (Kg; mean \pm SD [range]) & $3.1 \pm 0.5[1.06-5.3]$ \\
\hline Baby's length (cm; mean \pm SD [range]) & $49.5 \pm 2.7[34-62]$ \\
\hline $\begin{array}{l}\text { Baby's head circumference }(\mathrm{cm} \text {; mean } \pm S D \\
\text { [range]) }\end{array}$ & $34.1 \pm 1.9[26-52]$ \\
\hline
\end{tabular}

Table 1 Socio-demographic and clinical data of the study population (Continued)

\begin{tabular}{ll}
\hline APGAR score & $8.6 \pm 0.63$ [7-9] \\
Neonatal admission to ICU & $29(2.9)$ \\
Vitamin D level (nmol/L; mean \pm SD [range]) & $30.46 \pm 19.6$ [7.1-150] \\
aTotal number is below one thousand due to incomplete questionnaires; data \\
are expressed in number (percentage) unless specified; SD Standard deviation
\end{tabular}

and the majority had a severe form of deficiency ( $79 \%)$. In spite of this high figure, no study has been published in the kingdom of Saudi Arabia about the effect of vitamin D deficiency on maternal and birth outcomes.

The current study revealed that vitamin D deficiency was highly prevalent, mostly in the middle-aged pregnant women. Overall, vitamin D status had no relation to the risk of adverse pregnancy and neonatal outcomes. $25(\mathrm{OH}) \mathrm{D}$ concentrations showed no association with the risk of GDM while hypertensive disorders of pregnancy existed only in women with insufficient and deficient vitamin D. In addition, positive history of miscarriage was highly elevated in women with vitamin D insufficiency.

GDM was the most common maternal complication in this study. Its prevalence was consistent with that reported globally (4.1-27.5\%) [26]. Previous reports associated vitamin D deficiency with GDM $[27,28]$ and in several countries like Iran [29], Australia [30] and the United States [16]. On the contrary and similar to our results, no significant association was reported by Rodriguez et al. [31] and Flood-Nichols et al. [32] and in different countries too, e.g. India [33], the United Kingdom [34] and the United States [35]. It should be noted that vitamin $\mathrm{D}$ supplementation during early pregnancy decreased the incidence of GDM in women having vitamin D level below $80 \mathrm{nmol} / \mathrm{L}$, yet this frequency was not significant when compared to the one who did [36]. On the other hand, an association of vitamin D deficiency with impaired insulin secretion has been observed in different studies [37, 38]. Inadequate insulin secretion has been identified in rodents with vitamin D deficiency [39]. In addition, a significant correlation was described between 25(OH)D levels in pregnant women and insulin sensitivity or fasting blood glucose levels [40]. This might explain the weak negative correlation between fasting blood glucose and vitamin D levels in our study. A similar inverse correlation was also observed by Tsur et al. with more potency to the progression from normoglycemia to hyperglycemia in patients with severe vitamin D deficiency (levels less than $25 \mathrm{nmol} / \mathrm{L}$ ) [41].

Preeclampsia, an adverse effects ranging from 2 to $17 \%$ in pregnant women worldwide [42], has been diagnosed in less than $1 \%$ of our study population. Though, hypertensive disorders of pregnancy existed only in 
Table 2 Comparison of participants' data, pregnancy and neonatal outcomes according to their vitamin D status

\begin{tabular}{|c|c|c|c|c|}
\hline & $\begin{array}{l}\text { Normal vitamin D } \\
N=38\end{array}$ & $\begin{array}{l}\text { Insufficient vitamin D } \\
N=98\end{array}$ & $\begin{array}{l}\text { Deficient vitamin D } \\
N=864\end{array}$ & $P$ value \\
\hline \multicolumn{5}{|l|}{ Age groups distribution } \\
\hline Less than 25 years & $11(28.9)$ & $20(20.4)$ & $290(33.6)$ & \multirow[t]{3}{*}{$<0.01$} \\
\hline $25-35$ years & $13(34.2)$ & $52(53.1)$ & $448(52.0)$ & \\
\hline More than 35 & $14(36.8)$ & $26(26.5)$ & $124(14.4)$ & \\
\hline \multicolumn{5}{|l|}{ Nationality } \\
\hline Saudi & $32(84.2)$ & $85(86.7)$ & $782(90.5)$ & \multirow[t]{2}{*}{0.24} \\
\hline Non Saudi & $6(15.8)$ & $13(13.3)$ & $82(9.5)$ & \\
\hline \multicolumn{5}{|l|}{ Education } \\
\hline High school & $22(61.1)$ & $62(65.3)$ & $584(71.4)$ & \multirow[t]{2}{*}{0.32} \\
\hline University or higher & $14(38.9)$ & $33(34.7)$ & $234(28.6)$ & \\
\hline \multicolumn{5}{|l|}{ Working status } \\
\hline Housewife & $28(73.7)$ & $78(79.6)$ & $745(86.4)$ & \multirow[t]{2}{*}{0.02} \\
\hline Employee & $10(26.3)$ & $20(20.4)$ & $117(13.6)$ & \\
\hline \multicolumn{5}{|l|}{ Reproductive history } \\
\hline \multicolumn{5}{|l|}{ Parity } \\
\hline Primiparous & $12(31.6)$ & $24(24.5)$ & $287(32.2)$ & \multirow[t]{2}{*}{0.22} \\
\hline Multiparous & $26(68.4)$ & $74(75.5)$ & $577(66.8)$ & \\
\hline Positive history of miscarriage & $7(18.4)$ & $35(35.7)$ & $203(23.5)$ & 0.02 \\
\hline \multicolumn{5}{|l|}{ Status of current pregnancy } \\
\hline Pregnancy BMI $\left(\mathrm{Kg} / \mathrm{m}^{2} ;\right.$ mean $\left.\pm \mathrm{SD}\right)$ & $30.7 \pm 5.5$ & $30.7 \pm 6.2$ & $31.1 \pm 6.9$ & 0.66 \\
\hline Gestational diabetes & $5(13.5)$ & $12(13.3)$ & $94(12.0)$ & 0.8 \\
\hline Pre-Gestational Diabetes & $0(0.0)$ & $1(1.1)$ & $18(2.3)$ & 0.9 \\
\hline Pre-existing hypertension & $0(0.0)$ & $1(1.0)$ & $3(0.3)$ & 0.44 \\
\hline Gestational hypertension & $0(0.0)$ & $2(2.0)$ & $12(1.4)$ & 0.79 \\
\hline Preeclampsia & $0(0.0)$ & $0(0.0)$ & $9(1.0)$ & 0.28 \\
\hline Intrauterine growth restriction & $2(5.3)$ & $2(2.1)$ & $11(1.3)$ & 0.07 \\
\hline \multicolumn{5}{|l|}{ Delivery and neonatal outcomes } \\
\hline Preterm labour & $4(10.8)$ & $3(3.1)$ & $73(8.5)$ & 0.14 \\
\hline \multicolumn{5}{|l|}{ Mode of Delivery } \\
\hline Spontaneous & $29(76.3)$ & $76(77.6)$ & $663(76.7)$ & \multirow{3}{*}{0.71} \\
\hline Instrumental delivery & $1(2.6)$ & $4(4.1)$ & $56(6.5)$ & \\
\hline Caesarian section & $8(21.1)$ & $18(18.4)$ & $145(16.8)$ & \\
\hline Birth weight (Kg; mean $\pm \mathrm{SD}$ ) & $3.1 \pm 0.5$ & $3.2 \pm 0.4$ & $3.1 \pm 0.5$ & 0.67 \\
\hline Baby's length (cm; mean $\pm \mathrm{SD})$ & $49.5 \pm 2.2$ & $49.7 \pm 2.2$ & $49.5 \pm 2.8$ & 0.96 \\
\hline Head Circumference $(\mathrm{cm}$; mean $\pm \mathrm{SD})$ & $34.1 \pm 1.1$ & $34.4 \pm 1.7$ & $34.1 \pm 2.2$ & 0.6 \\
\hline APGAR score (mean \pm SD) & $8.3 \pm 1.9$ & $8.9 \pm 0.3$ & $8.8 \pm 0.8$ & 0.05 \\
\hline Neonatal admission to ICU & $1(2.6)$ & $0(0.0)$ & $28(3.3)$ & 0.18 \\
\hline
\end{tabular}

Data are expressed in number (percentage) unless specified; SD Standard deviation

pregnant women with insufficient and deficient vitamin D. Vitamin D and sunlight may have a role in the incidence of preeclampsia that is more frequent in winter than summer [43]. Nonetheless, controversy remains about the relationship of vitamin $\mathrm{D}$ deficiency with preeclampsia [44], and on the effectiveness of vitamin
D supplementation in reducing its risk during pregnancy [45].

Apparently, low 25(OH)D concentrations were not associated with birth and neonatal adverse effects in our study. Despite the paucity of research studying pregnancy outcomes in relation to vitamin D status, several 


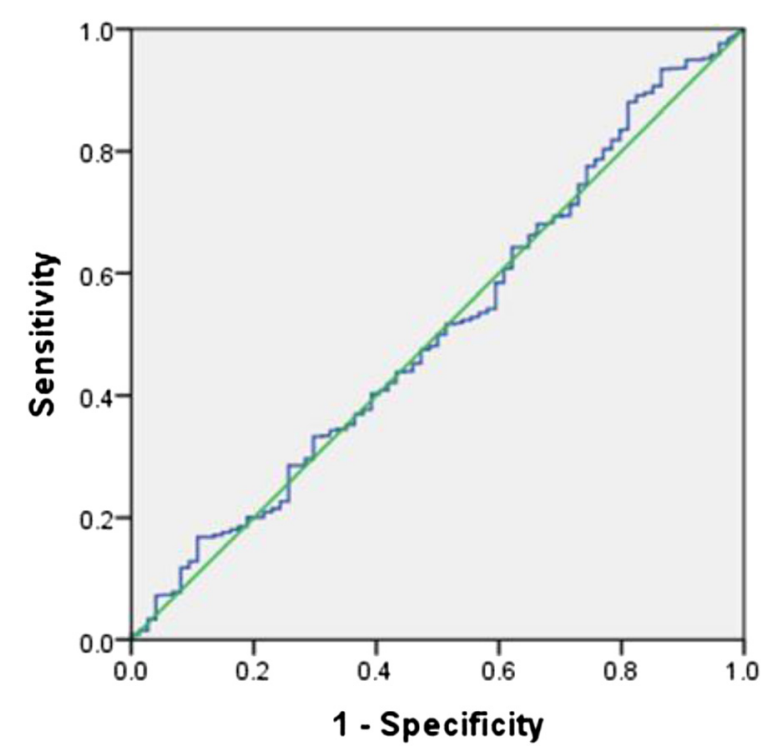

Fig. 1 ROC curve analysis of serum Vitamin $D$ and its relation to normal pregnancy outcome discrimination. AUROC curve: 0.51; $95 \%$ confidence interval (Cl): 0.44-0.58; $p=0.8$

studies recorded findings similar to our results [31, 46, 47]. However, the high frequency of history of miscarriage identified in this research was associated mainly with vitamin D insufficiency. Previous studies attempted to examine the role of low vitamin D in complications like preterm delivery or infertility with no records on its relation to miscarriage. The high rate of history of miscarriage detected herein might be related to the proposed regulatory role of vitamin $\mathrm{D}$ ingenes associated with placental invasion, normal implantation, and angiogenesis [48]. In addition, vitamin D may play a potential role in the prevention of miscarriage due to its combined immunomodulatory and antiinflammatory properties during early pregnancy [49]. Another factor is the high association of vitamin D deficiency with infectious diseases, specifically with bacterial vaginosis [50]. Whatever their types or sites, these infections represent a major risk to the maternal health and might lead to serious pregnancy adverse outcomes.

Pregnancy is a special condition during which the body experiences several physiological alterations, including changes in vitamin D metabolism. The effect of vitamin D deficiency on maternal and neonatal health is still under investigations. The controversy between the results of documented studies did not give obvious clues to the real association of hypovitaminosis $\mathrm{D}$ with maternal and neonatal complications [51]. So far, vitamin D supplementation during pregnancy had no effect on the incidence of adverse effects like preeclampsia, GDM, preterm birth, small-for-gestational-age infants, and cesarean section [45]. Nevertheless, these data were retrieved from trials conducted on populations living in the northern latitudes. It cannot be generalized to countries like Saudi Arabia, where there is enough sun exposure. Though sartorial parameters like the cultural practice of complete covering of the body, head and even face, in addition to the restriction of outdoors activities, might counteract this positive effect of the ample sunlight $[24,52,53]$. It is highly recommended putting into consideration each population characteristic while investigating the role of hypovitaminosis $\mathrm{D}$ in relation to pregnancy outcome. Factors such as geographic location
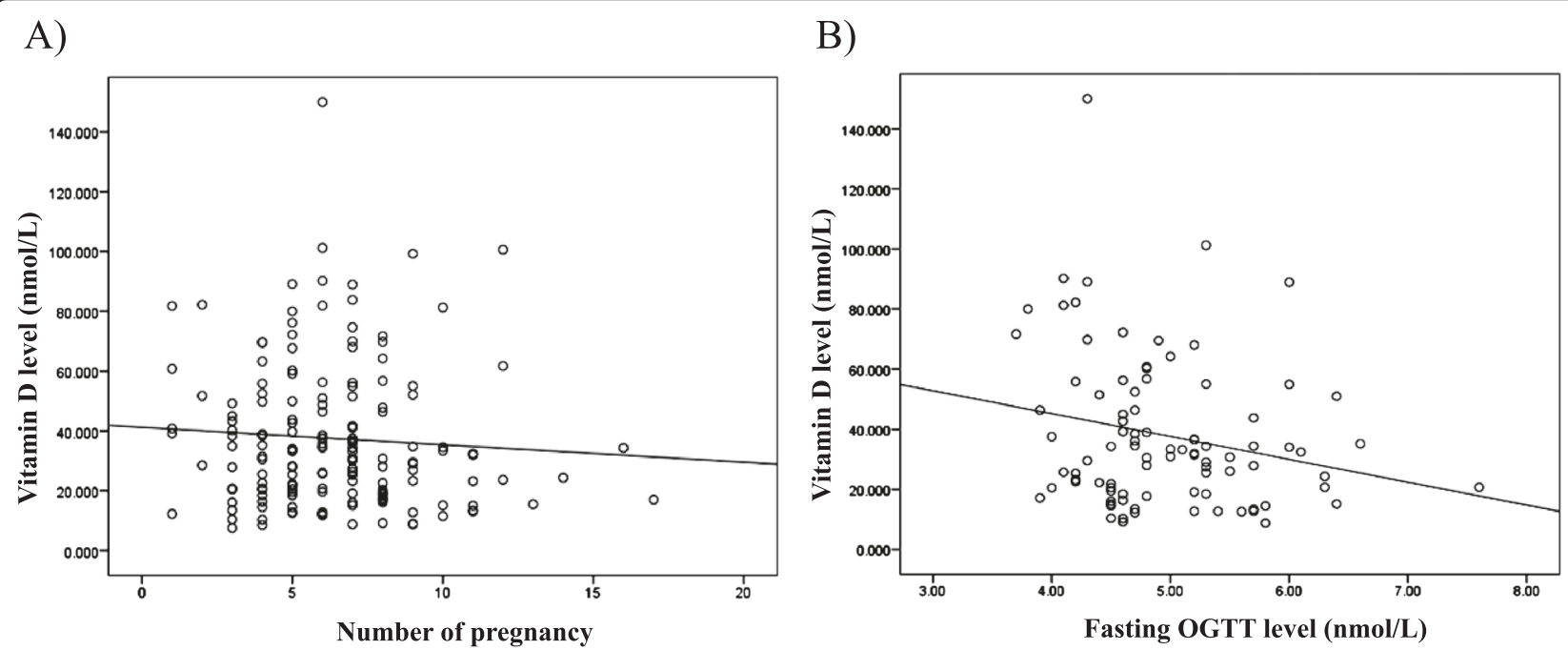

Fig. 2 Correlation between vitamin D levels and pregnancy status. a A weak negative correlation between vitamin $D$ levels and parity $(r=-0.07$, $p=0.3$ ). $\mathbf{b}$ A significant negative correlation between the vitamin $\mathrm{D}$ levels and the fasting levels of oral glucose tolerance test (OGTT) among females aging more than 35-year-old $(r=-0.2, p=0.03)$ 
and latitude, ethnicity, skin phenotype and individual response to UV, age, physical activity and poor diet have to be interpreted cautiously $[8,51,53]$. Even vitamin D supplementation should be adjusted in relation to the population reference baseline, especially in pregnant women residing in countries with high prevalence of hypovitaminosis D like Saudi Arabia [51].

Maternal vitamin $\mathrm{D}$ levels vary during gestation. Serum $1,25(\mathrm{OH}) \mathrm{D}$ increases normally from the end of the first trimester and reaches its maximum level in the third trimester [54]. However, associated increase in 25(OH)D levels could not be identified [55]. Moreover, Vitamin D action is affected by factors like its metabolism and other hormonal and metabolic pathways [56]. It can be speculated that factors other than vitamin D can determine maternal and neonatal outcomes. Furthermore, vitamin $\mathrm{D}$ action is also dependent on its interaction with its binding protein and its receptor [56]. In fact, genetic variations (e.g. Vitamin D receptor polymorphisms) can be involved in vitamin D metabolism and in disease susceptibility [57]. Such population differences could explain the disparity in data published regarding the effect of vitamin D on pregnancy outcomes. Finally, the increased oxidative stress associated with any placental dysfunction causes an alteration in the expression of vitamin D-binding protein and vitamin D receptors [58] that subsequently can alter the vitamin $\mathrm{D}$ action.

This study provided novel information about the relation of vitamin D status and pregnancy outcomes in the Saudi population. It was conducted on a large sample size, yet it had some limitations. Data of vitamin D concentrations during early pregnancy were not available as pregnant women were reluctant to follow up in governmental hospitals. Confounders like pre-pregnancy BMI, lifestyle and physical activity were not investigated. Our data revealed that vitamin D deficiency has no effect on the risk of adverse pregnancy and birth outcomes. However, the study design is of cross-sectional nature; this hindered the confirmation of the causal relationship between vitamin D levels and history of miscarriage, a common unfavorable pregnancy outcome reported in this research.

\section{Conclusion}

The study underscores the importance of measurement of serum 25(OH)D within the Saudi population. Nevertheless, hypovitaminosis D showed no relation to adverse pregnancy outcomes in this research. Regardless of all associations or correlation studies that have been published, none can give a direct proof of the causality of vitamin $\mathrm{D}$ deficiency in different pregnancy outcomes. Further interventional and experimental studies must be conducted to clarify the exact implication of vitamin D in inducing these adverse effects. In addition, a prospective study is needed to give stronger evidence on the suggested correlation between vitamin D and miscarriage. Although there is a lack of agreement on the need for vitamin D intake during pregnancy, vitamin supplementation is still recommended until this dilemma is deciphered.

\section{Ethics and consent}

The study was conducted in accordance with the guidelines of the Declaration of Helsinki and was approved by the Institutional Review Board (IRB) of King Saud University (Approval number: E-10-218).

All pertinent study information was explained to them and they were informed that rejection or withdrawal from the study will not affect any medical service provided. A summarized study information sheet was shown to all cases before obtaining their verbal agreement. Finally, an informed verbal consent was obtained and witnessed by the attending nurse. A log book was created including the participant's study number and the date of consent. The IRB waived the requirement for taking a written consent as the research had minimal risk of harm to subjects and involved no risky procedures for which written consent is required.

\section{Additional files}

Additional file 1: STROBE Statement. (DOC $92.5 \mathrm{~kb}$ )

\section{Abbreviations}

1,25(OH)2D: 1,25-dihydroxy vitamin D; 25(OH)D: 25-hydroxyvitamin D; AUC: area under the curve; BMI: body mass index; Cl: confidence interval; ELISA: enzyme-linked immunosorbent assay; GDM: gestational diabetes mellitus; ICU: intensive care unit; IRB: Institutional Review Board; KKUH: King Khaled University Hospital; OGTT: oral glucose tolerance test; ROC: receiver operating characteristic; SD: standard deviation; VDR: vitamin D receptors.

\section{Acknowledgements}

None.

Funding

None declared.

\section{Availability of data and materials}

Data are available from King Khaled University Hospital, King Saud Univeristy for researchers who meet the criteria for access to confidential data. Data is restricted to protect participant privacy. Any interested researcher can obtain a minimal data-set after contacting one of the main authors: GA or Gl. GA can be contacted at ghadeer-alshaikh@hotmail.com and Gl can be contacted at gehan_amer@med.suez.edu.eg.

\section{Authors' contributions}

GA conceived the idea of the study, collected data, drafted the manuscript and gave the final approval for the manuscript to be published. Gl participated in data analysis and interpretation and drafted the manuscript. AF designed the protocol, carried out the statistical analysis and shared in writing the manuscript draft. HA shared in data collection and reviewed the article. All authors reviewed and approved the final manuscript.

\section{Competing interests}

The authors have declared that they have no competing interests. 


\section{Author details}

'Obstetrics and Gynecology Department, College of Medicine, King Khalid University Hospital, King Saud University, Riyadh, Kingdom of Saudi Arabia. ${ }^{2}$ College of Medicine, Princess Nourah Bint Abdulrahman University, Riyadh, Kingdom of Saudi Arabia. ${ }^{3}$ Department of Medical Biochemistry, Faculty of Medicine, Suez Canal University, Round Road, Ismailia 41511, Egypt. ${ }^{4}$ Department of Biostatistics, High Institute of Public Health, Alexandria University, Alexandria, Egypt.

Received: 26 November 2015 Accepted: 7 May 2016 Published online: 24 May 2016

\section{References}

1. Kulie T, Groff A, Redmer J, Hounshell J, Schrager S. Vitamin D: an evidence-based review. J Am Board Fam Med. 2009;22:698-706.

2. Holick MF. The role of vitamin D for bone health and fracture prevention. Curr Osteoporos Rep. 2006;4:96-102.

3. Malone RW, Kessenich C. Vitamin D deficiency: implications across the lifespan. J Nurs Pract. 2008;4:448-54

4. Gallagher JC, Sai AJ. Vitamin D insufficiency, deficiency, and bone health J Clin Endocrinol Metab. 2010;95:2630-3.

5. Cannell JJ, Hollis BW. Use of vitamin D in clinical practice. Altern Med Rev. 2008;13:6-20.

6. Adams JS, Hewison M. Unexpected actions of vitamin D: new perspectives on the regulation of innate and adaptive immunity. Nat Clin Pract Endocrinol Metab. 2008:4:80-90.

7. Holick MF, Chen TC. Vitamin D deficiency: a worldwide problem with health consequences. Am J Clin Nutr. 2008;87:1080S-6S.

8. Thacher TD, Clarke BL. Vitamin D insufficiency. Mayo Clin Proc. 2011:86:50-60.

9. Al-Mogbel ES. Vitamin D, status among Adult Saudi Females visiting Primary Health Care Clinics. Int J Health Sci (Qassim). 2012;6:116-26.

10. Hussain AN, Alkhenizan AH, El Shaker M, Raef H, Gabr A. Increasing trends and significance of hypovitaminosis D: a population-based study in the Kingdom of Saudi Arabia. Arch Osteoporos. 2014;9:190.

11. Siddiqui AM, Kamfar HZ. Prevalence of vitamin D deficiency rickets in adolescent school girls in Western region, Saudi Arabia. Saudi Med J. 2007;28:441-4.

12. McKenna MJ. Differences in vitamin D status between countries in young adults and the elderly. Am J Med. 1992;93:69-77.

13. Holmes VA, Barnes MS, Alexander HD, McFaul P, Wallace JM. Vitamin D deficiency and insufficiency in pregnant women: a longitudinal study. $\mathrm{Br} J$ Nutr. 2009;102:876-81.

14. Dawodu A, Wagner CL. Mother-child vitamin D deficiency: an international perspective. Arch Dis Child. 2007;92:737-40.

15. Sayers A, Tobias JH. Estimated maternal ultraviolet B exposure levels in pregnancy influence skeletal development of the child. J Clin Endocrinol Metab. 2009;94:765-71

16. Zhang C, Qiu C, Hu FB, David RM, van Dam RM, Bralley A, et al. Maternal plasma 25-hydroxyvitamin D concentrations and the risk for gestational diabetes mellitus. PLoS One. 2008:3:e3753.

17. Brown MA, Lindheimer MD, de Swiet M, Van Assche A, Moutquin JM. The classification and diagnosis of the hypertensive disorders of pregnancy: statement from the International Society for the Study of Hypertension in Pregnancy (ISSHP). Hypertens Pregnancy. 2001;20:IX-XIV.

18. Holick MF. Vitamin D, deficiency. N Engl J Med. 2007:357:266-81.

19. Holick MF, Binkley NC, Bischoff-Ferrari HA, Gordon CM, Hanley DA, Heaney $\mathrm{RP}$, et al. Evaluation, treatment, and prevention of vitamin D deficiency: an Endocrine Society clinical practice guideline. J Clin Endocrinol Metab. 2011:96:1911-30.

20. Burris HH, Camargo Jr CA. Vitamin D and Gestational Diabetes Mellitus. Curr Diab Rep. 2014;14:451

21. Jorde R, Grimnes G. Vitamin D and health: the need for more randomized controlled trials. J Steroid Biochem Mol Biol. 2015;148:269-74.

22. Moon R, Harvey N, Cooper C. ENDOCRINOLOGY IN PREGNANCY: influence of maternal vitamin D status on obstetric outcomes and the foetal skeleton. Eur J Endocrinol. 2015;173:R69-83.

23. Al-Daghri NM, Al-Attas OS, Al-Okail MS, Alkharfy KM, Al-Yousef MA, Nadhrah $\mathrm{HM}$, et al. Severe hypovitaminosis D is widespread and more common in non-diabetics than diabetics in Saudi adults. Saudi Med J. 2010;31:775-80.
24. Al-Daghri NM, Al-Attas OS, Alokail MS, Alkharfy KM, Yakout SM, Aljohani $\mathrm{NJ}$, et al. Lower vitamin D status is more common among Saudi adults with diabetes mellitus type 1 than in non-diabetics. BMC Public Health. 2014;14:153.

25. Ardawi MS, Qari MH, Rouzi AA, Maimani AA, Raddadi RM. Vitamin D status in relation to obesity, bone mineral density, bone turnover markers and vitamin D receptor genotypes in healthy Saudi pre- and postmenopausal women. Osteoporos Int. 2011;22:463-75.

26. Guariguata L, Linnenkamp U, Beagley J, Whiting DR, Cho NH. Global estimates of the prevalence of hyperglycaemia in pregnancy. Diabetes Res Clin Pract. 2014;103:176-85.

27. Bener A, Al-Hamaq AO, Saleh NM. Association between vitamin D insufficiency and adverse pregnancy outcome: global comparisons. Int J Womens Health. 2013;5:523-31.

28. Wei SQ, Qi HP, Luo ZC, Fraser WD. Maternal vitamin D status and adverse pregnancy outcomes: a systematic review and meta-analysis. J Matern Fetal Neonatal Med. 2013;26:889-99.

29. Hossein-Nezhad A, Maghbooli Z, Vassigh AR, Larijani B. Prevalence of gestational diabetes mellitus and pregnancy outcomes in Iranian women. Taiwan J Obstet Gynecol. 2007:46:236-41.

30. Clifton-Bligh RJ, McElduff $P$, McElduff A. Maternal vitamin D deficiency, ethnicity and gestational diabetes. Diabet Med. 2008;25:678-84.

31. Rodriguez A, Garcia-Esteban R, Basterretxea M, Lertxundi A, Rodriguez-Bernal C, Iniguez C, et al. Associations of maternal circulating 25-hydroxyvitamin D3 concentration with pregnancy and birth outcomes. BJOG. 2015;122:1695-704.

32. Flood-Nichols SK, Tinnemore D, Huang RR, Napolitano PG, Ippolito DL. Vitamin D deficiency in early pregnancy. PLoS One. 2015:10:e0123763.

33. Farrant HJ, Krishnaveni GV, Hill JC, Boucher BJ, Fisher DJ, Noonan K, et al. Vitamin D insufficiency is common in Indian mothers but is not associated with gestational diabetes or variation in newborn size. Eur J Clin Nutr. 2009;63:646-52

34. Makgoba M, Nelson SM, Savvidou M, Messow CM, Nicolaides K, Sattar N. First-trimester circulating 25-hydroxyvitamin D levels and development of gestational diabetes mellitus. Diabetes Care. 2011;34:1091-3.

35. Baker AM, Haeri S, Camargo Jr CA, Stuebe AM, Boggess KA. First-trimester maternal vitamin D status and risk for gestational diabetes (GDM) a nested case-control study. Diabetes Metab Res Rev. 2012;28:164-8.

36. Yap C, Cheung NW, Gunton JE, Athayde N, Munns CF, Duke A, et al. Vitamin D supplementation and the effects on glucose metabolism during pregnancy: a randomized controlled trial. Diabetes Care. 2014;37:1837-44

37. Mathieu C, Gysemans C, Giulietti A, Bouillon R. Vitamin D and diabetes. Diabetologia. 2005:48:1247-57.

38. Liu E, Meigs JB, Pittas AG, McKeown NM, Economos CD, Booth SL, et al. Plasma 25-hydroxyvitamin d is associated with markers of the insulin resistant phenotype in nondiabetic adults. J Nutr. 2009;139:329-34.

39. Norman AW, Frankel JB, Heldt AM, Grodsky GM. Vitamin D deficiency inhibits pancreatic secretion of insulin. Science. 1980;209:823-5.

40. Maghbooli Z, Hossein-Nezhad A, Karimi F, Shafaei AR, Larijani B. Correlation between vitamin D3 deficiency and insulin resistance in pregnancy. Diabetes Metab Res Rev. 2008;24:27-32.

41. Tsur A, Feldman BS, Feldhammer I, Hoshen MB, Leibowitz G, Balicer RD. Decreased serum concentrations of 25-hydroxycholecalciferol are associated with increased risk of progression to impaired fasting glucose and diabetes. Diabetes Care. 2013:36:1361-7.

42. Roberts CL, Ford JB, Algert CS, Antonsen S, Chalmers J, Cnattingius S, et al. Population-based trends in pregnancy hypertension and pre-eclampsia: an international comparative study. BMJ Open. 2011;1:e000101.

43. Marwaha RK, Tandon N, Chopra S, Agarwal N, Garg MK, Sharma B, et al. Vitamin D status in pregnant Indian women across trimesters and different seasons and its correlation with neonatal serum 25-hydroxyvitamin D levels. Br J Nutr. 2011:106:1383-9.

44. Bodnar LM, Simhan HN, Catov JM, Roberts JM, Platt RW, Diesel JC, et al. Maternal vitamin D status and the risk of mild and severe preeclampsia. Epidemiology. 2014;25:207-14.

45. Perez-Lopez FR, Pasupuleti V, Mezones-Holquin E, Benites-Zapata VA, Thota $P$, Deshpande $A$, et al. Effect of vitamin D supplementation during pregnancy on maternal and neonatal outcomes: a systematic review and meta-analysis of randomized controlled trials. Fertil Steril. 2015;103:1278-88.

46. Schneuer FJ, Roberts CL Guilbert C, Simpson JM, Algert CS, Khambalia AZ, et al. Effects of maternal serum 25-hydroxyvitamin D concentrations in the 
first trimester on subsequent pregnancy outcomes in an Australian population. Am J Clin Nutr. 2014;99:287-95.

47. Zhou J, Su L, Liu M, Liu Y, Cao X, Wang Z, et al. Associations between 25-hydroxyvitamin D levels and pregnancy outcomes: a prospective observational study in southern China. Eur J Clin Nutr. 2014;68:925-30

48. Evans KN, Bulmer JN, Kilby MD, Hewison M. Vitamin D and placentaldecidual function. J Soc Gynecol Investig. 2004;11:263-71.

49. Liu NQ, Hewison M. Vitamin D, the placenta and pregnancy. Arch Biochem Biophys. 2012;523:37-47.

50. Hensel KJ, Randis TM, Gelber SE, Ratner AJ. Pregnancy-specific association of vitamin D deficiency and bacterial vaginosis. Am J Obstet Gynecol. 2011;204:41.

51. Karras SN, Anagnostis P, Naughton D, Annweiler C, Petroczi A, Goulis DG. Vitamin D during pregnancy: why observational studies suggest deficiency and interventional studies show no improvement in clinical outcomes? A narrative review. J Endocrinol Invest. 2015;38:1265-75.

52. Thorne-Lyman A, Fawzi WW. Vitamin D during pregnancy and maternal, neonatal and infant health outcomes:a systematic review and meta-analysis. Paediatr Perinat Epidemiol. 2012;26:75-90.

53. Karras SN, Anagnostis P, Annweiler C, Papadopoulou F, Persynaki A, Goulis DG. Maternal vitamin D status during pregnancy: the Mediterranean reality. Eur J Clin Nutr. 2014:68:864-9.

54. Brannon PM, Picciano MF. Vitamin D in pregnancy and lactation in humans. Annu Rev Nutr. 2011;31:89-115.

55. Kovacs CS. Vitamin D, in pregnancy and lactation: maternal, fetal, and neonatal outcomes from human and animal studies. Am J Clin Nutr. 2008; 88:520S-8S

56. Colonese F, Lagana AS, Colonese E, Sofo V, Salmeri FM, Granese R, et al. The pleiotropic effects of vitamin D in Gynaecological and obstetric diseases: an overview on a Hot topic. Biomed Res Int. 2015;2015:986281.

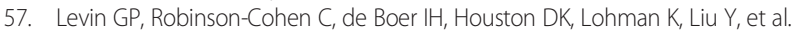
Genetic variants and associations of 25-hydroxyvitamin D concentrations with major clinical outcomes. JAMA. 2012;308:1898-905.

58. Ma R, Gu Y, Zhao S, Sun J, Groome LJ, Wang Y. Expressions of vitamin D metabolic components VDBP, CYP2R1, CYP27B1, CYP24A1, and VDR in placentas from normal and preeclamptic pregnancies. Am J Physiol Endocrinol Metab. 2012;303:E928-35.

\section{Submit your next manuscript to BioMed Central and we will help you at every step:}

- We accept pre-submission inquiries

- Our selector tool helps you to find the most relevant journal

- We provide round the clock customer support

- Convenient online submission

- Thorough peer review

- Inclusion in PubMed and all major indexing services

- Maximum visibility for your research

Submit your manuscript at www.biomedcentral.com/submit 